\title{
Lutero, Müntzer e a Revolução do Homem Comum (1524-1525)
}

\author{
Luther, Müntzer and the Revolution of the common man (1524-1525)
}

\section{Marcos José de Araújo Caldas}

Doutor em Históra

Professor da Universidade Federal Rural do Rio de Janeiro marcos.caldas@gmail.com

Resumo: A guerra dos camponeses alemães, que durou de 1524 a 1525 , foi conhecida como 'o maior evento natural da história do Estado Alemão' (Leopond von Ranke). Desde pelo menos o século XVIII as guerras camponesas na Alemanha produziram uma vasta bibliografia com diferentes interpretações. Este pequeno ensaio analisa as tendências da historiografia atual sobre o assunto e traz uma proposta de tradução dos famosos 12 artigos dos camponeses da Suábia Superior, considerados um dos mais importantes documentos dos direitos humanos e das liberdades civis após a queda do império romano.

Palavras-chaves: Guerras Camponesas, Lutero, Müntzer, Doze Artigos, Revolução do Homem Comum.

\begin{abstract}
The German peasants' war, lasting from 1524 to 1525 , was known as the greatest natural event in the history of the German State (L. von Ranke). Since at least the XVIIIth century it produced a volumous bibliography with different interpretations. This article examinates the tendences of nowaday historiography about the subject and it brings a translation for the famous Twelve Articles of the Peasants of the Upper Swabia considered one of the most important documents of human rigths and civil liberties after the fall of Roman Empire.
\end{abstract}

Key words: German peasents' war, Luther, Müntzer, Twelve Articles, Common Man Revolution. 


\section{Figura I}

Xilogravura de memorial, em forma de coluna, das guerras camponesas feita por Albrech Dürer por volta de 1526.

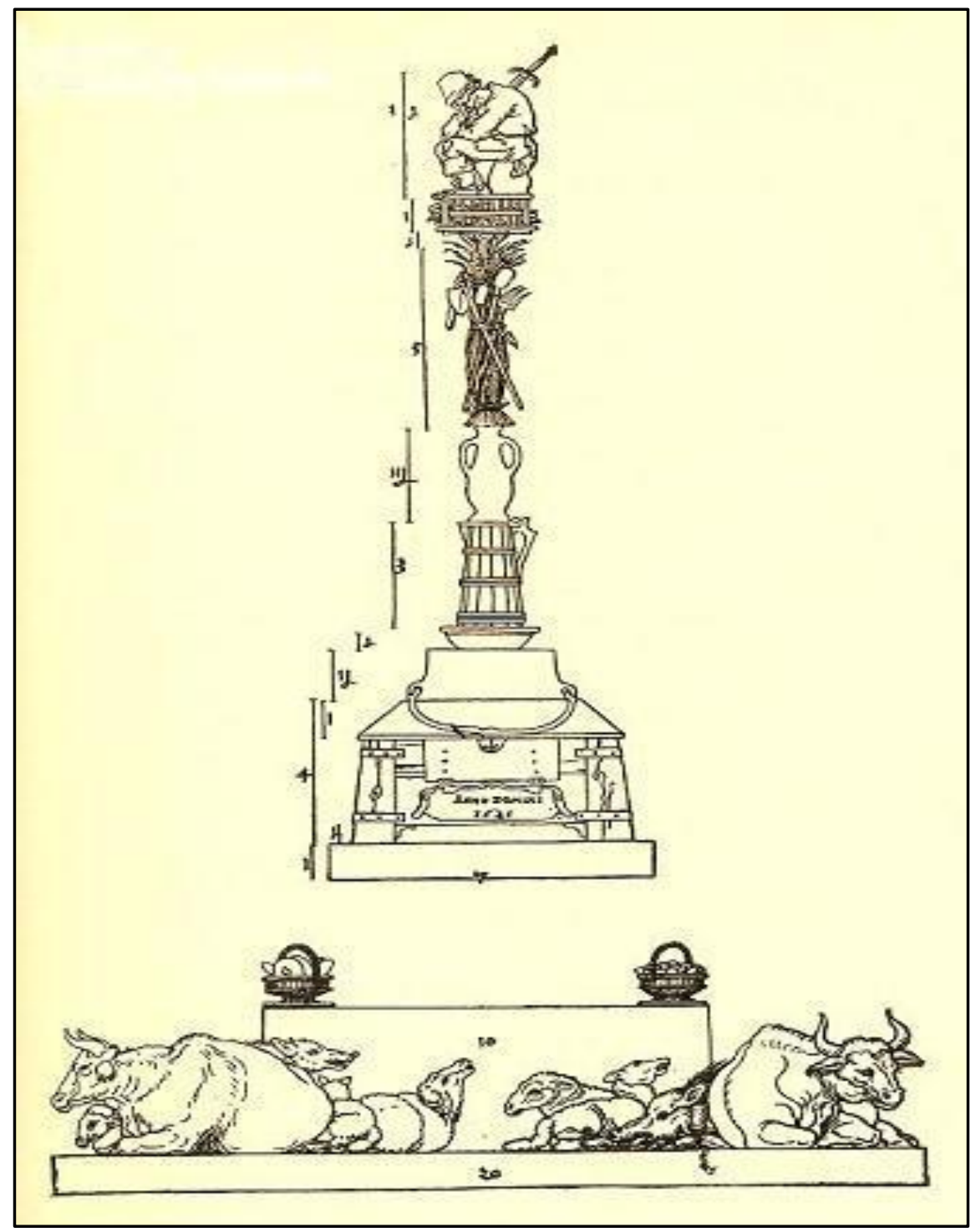

Fonte: Albrecht Dürers Arbeiten zum Thema Bauern. Disponível em: <http://www.bauernkriege.de/duerer.html>. Acesso: 31 nov. 2018. 
“Por que crê em Deus a Burguesia?” (LAFARGUE,1985) ${ }^{1}$. Esta certamente não é uma pergunta de fácil resposta e tampouco uma pergunta retórica, e isto porque os temas que subjazem aos termos inquiridos são tão díspares e polissêmicos que possivelmente não há duas pessoas que entrariam em acordo sobre tais. Temos que adotar método e teoria se quisermos respondê-la, mesmo assim com um grande risco de não satisfazer a questão que ali se levanta. O primeiro passo, a meu ver, é que seria preciso definir Burguesia. O segundo é contextualizá-la. E o terceiro e mais difícil é indagar-se: esta pergunta é realmente válida? Para P. Lafargue, autor do livro cujo título inicia este texto, a resposta é simples: “O cristianismo (...) é por excelência a religião das sociedades que se baseiam sobre a propriedade privada e a exploração do trabalho assalariado" (LAFARGUE, 1985: 10) e como a exploração da propriedade privada e da mão de obra proletária se dá por necessidade econômica e não por submissão voluntária, nada mais natural para a burguesia do que recorrer à crença em Deus como um mecanismo de controle da grande massa de trabalhadores por meio da sujeição e da obediência. Por isso a Burguesia, beneficiária direta da exploração do homem sobre o homem, "crê" em Deus como mero instrumento de controle. Talvez o assunto merecesse mais reflexão de nossa parte. E isso por dois motivos, apenas para começar: em primeiro lugar, se o que foi dito acima for adequado, como explicar que boa parte dos camponeses agem em nome de Deus, da crença em Deus, e contra os anticristãos? Ou, dito de outro modo: como esclarecer que a crença seja responsável pelos mecanismos de controle da burguesia e, simultaneamente, esteja entre os fundamentos das mais agudas revoltas? Em segundo lugar, seria possível uma burguesia ou uma ideologia burguesa, em pleno século XVI, esvaziada de qualquer espiritualidade? Ou seja, seria possível pensar em uma classe ou segmento social acima da conjuntura espiritual que a cerca? Segundo Régine Pernoud em les origines de la bourgeoisie (PERNOUD, 1965) o burguês, como um tipo novo de indivíduo, é um fenômeno do século $\mathrm{X}$ de nossa Era e que paulatinamente adquire feições de um segmento social com consciência ideológica consistente entre os séculos XIII e XVI, ganhando autonomia perante o poder real e o poder eclesiástico. Portanto, será no fim deste período, no século XVI, que podemos identificar a burguesia como classe social, participando das grandes descobertas, e estendendo sua atividade comercial às novas terras. Este foi um argumento decisivo para que, no verão de 1850 em Hamburgo, na Alemanha, Friedrich Engels (1820-1895) viesse a publicar no periódico "Nova Gazeta

\footnotetext{
${ }^{1}$ O livro saiu com o título de: Causes de la croyance en Dieu / Paul Lafargue - Paris : Edition de la vie
} Socialiste, 1905. 
Renana, revista de Economia Política", dirigida por Karl Marx, em seus números 5 e 6 , uma de suas mais famosas obras Der deutsche Bauernkrieg - A guerra dos camponeses alemães.

\section{Figura 2}

Fac-simile da capa da $2^{\mathrm{a}}$. edição de 1870 de as guerras camponesas.

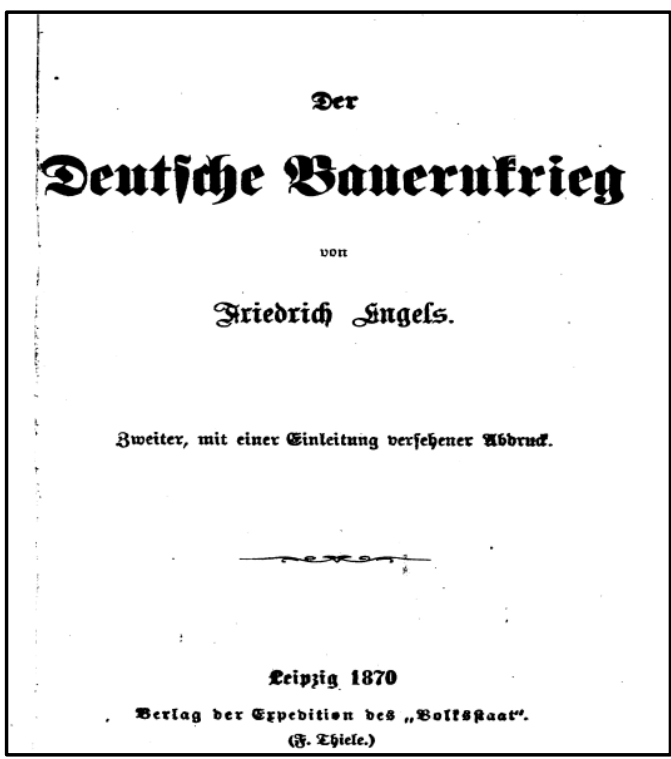

Fonte: Google Books. Disponível em:

<https://books.google.co.il/books?id=GW_TAAAAMAAJ\&printsec=frontcover\&hl=pt

-BR\&source=gbs_ge_summary_r\&cad=0\#v=onepage \&q\&f=false>. Acesso 31 nov. 2018.

Nela o autor disserta sobre as razões que levaram a uma série de levantes de camponeses e de segmentos da população mais humilde das cidades de várias regiões de fala alemã entre os anos de 1524 e 1526 a se revoltarem contra o status quo vigente. Os levantes tornaram-se ferozes especialmente nas regiões da Suábia, na Turíngia, no Tirol e regiões alpinas e em partes do vale do Reno, especialmente à montante, e haviam sido precedidos por uma outra série de revoltas, entre os anos de 1522 e 1523, conduzidas por segmentos da baixa nobreza, chamadas pela historiografia moderna de Revoltas dos Cavaleiros (Ritteraufstände), que reivindicavam, entre outras coisas, a diminuição dos encargos tributários. 


\section{Imagem 3:}

Regiões onde ocorreram os conflitos entre os anos de 1522 - Ritteraufstand (revolta dos cavaleiros, em verde) - a 1526 - Bauernkrieg (guerra dos camponeses, tendo como foco principal a região em vermelho).

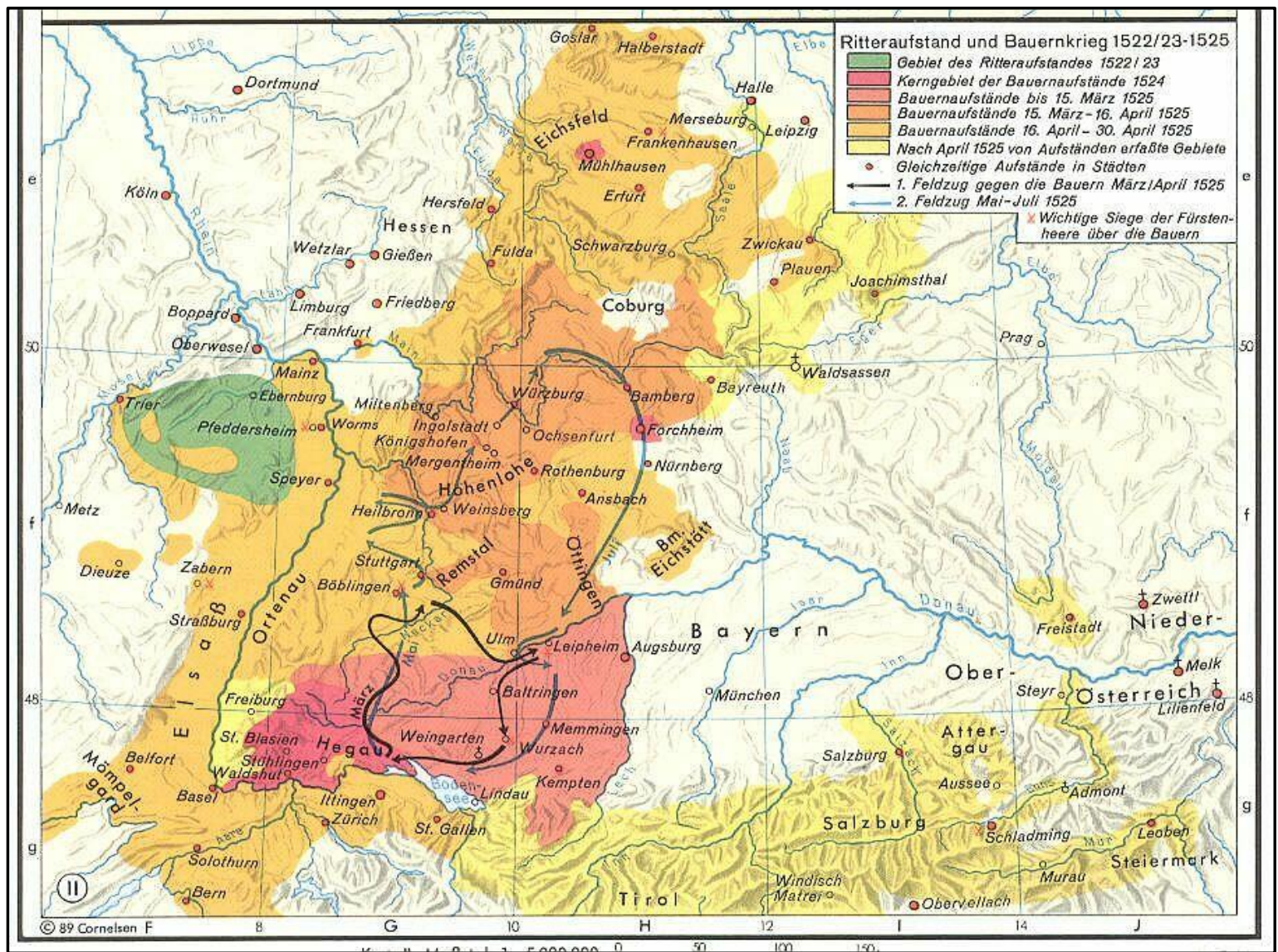

Fonte: Fränkisches Thüringen. Disponível em:

<http://fraenkischesthueringen.blogspot.com/2017/02/der-bauernkrieg-im-

hennebergischen.html>. Acesso em: 31 nov. 2018.

Porém os levantes dos camponeses eram de outra natureza. Tanto o foram que chamaram a atenção dos intelectuais do século XIX, como de F. Engels e Leopond von Ranke, o qual já em 1839 sentenciara: “a guerra dos camponeses foi o maior acontencimento natural da história alemã” (RANKE, 1909: 147) . Assim, desde então², mas principalmente após a publicação de A Guerra dos Camponeses Alemães de Engels,

\footnotetext{
${ }^{2}$ No século XVIII, há pelo menos uma obra dedicada à Guerra dos Camponese: SARTORIUS, GEROG FRIEDRICH. Versuch einer Geschichte des Deutschen Bauernkriegs oder der Empörung in Deutschland zu Anfang des sechszehnten Jahrhunderts. Berlim: Unger, 1795.
} 
os levantes dos camponeses passaram a frequentar a historiografia, em especial na cena alemã, onde um historiador chegou a computar 400 títulos sobre o assunto entre os anos de 1974 e 1976! (THOMAS, 1976;1977). A abundância em títulos reflete as divergentes interpretações sobre o assunto há mais de 150 anos, desde a primeira edição da obra de Engels.

Atualmente, divide-se a historiografia sobre a Guerra Camponesa em três grandes linhas (HOCKERTS, 1979: 1-20):

a) A primeira delas afirma que a Reforma e a Guerra dos Camponeses são parte de um mesmo processo revolucionário e diz respeito à passagem do Feudalismo para o Capitalismo. Por isso, são chamadas de "revolução burguesa primiva". Esta primeira linha de interpretação subtrai seus argumentos de um modelo conceitual de revolução marxista-leninista, segundo o qual a existência de um antagonismo entre as relações de produção e as novas forças produtivas, que mais amplamente são vistas em um contexto de crise da sociedade como um todo e da substituição destes fatores objetivos em direção a uma consciência revolucionária. Obviamente, nem todos os movimentos camponeses da baixa idade média caem na vala comum do conceito de revolução, uma vez que apenas sob aquelas condições do Capitalismo Primevo - forças produtivas capitalistas x relações feudais de produção - podem caracterizer uma revolução de fato. O problema que surge aqui é de 3 ordens: 1) é possível falar em crise da sociedade feudal como um todo? 2) o conceito de Capitalismo Primevo é aplicável a todo sistema? 3) Como os fatores culturais (humanismo, renascimento) interagiam perante as forças conservadoras do momento? As questões aqui suscitadas deixam mais lacunas do que respostas, até porque falar de Burguesia Revolucionária para o momento parece longe da compreensão do processo. Se do ponto de vista teórico metodológico encontramos problemas, o que dizer da qualidade e quantidade das fontes para a tese em tela? Em geral, o que temos são dados fragmentados e não seriais, e, portanto, trabalha-se com modelos e dinâmicas de longa duração do comportamento econômico da sociedade e da economia, algo que não é exclusivo para o Sacro Império Romano Germânico (KULA, 1962) $)^{3}$. E a Burguesia? E Lutero? E Müntzer? A burguesia era reformista e

\footnotetext{
${ }^{3}$ Os dados desta obra, como informa o autor, sobre a sociedade feudal polonesa do século XVI são do século XVIII.
} 
Lutero o seu lacaio. Com a palavra o próprio Engels: "A Lutero, reformador burguês, opúnhamos Münzer, revolucionário plebeu”.

b) Uma outra linha de pensamento é aquela que advoga um conflito em nível ideológico entre o direito consuetudinário popular milenar e um novo direito senhorial dos magistrados elou das autoridades (FRANZ. 1933: 11). No interior desta vertente estava a reação às idéias concebidas a priori sobre a base econômica das revoltas (acima). Nesta linha de pensamento, a Guerra Camponesa aparece como uma luta de duas esferas: a do Direito e a da Política. Por isso, para a maioria dos autores, tratava-se do que se chamava de "Revolução Conservadora" que "se situava mais no passado do que no futuro" (ZORN, 1971: 480), e com uma "concepção totalmente reacionária de Estado" (ANGERMEIER, 1966: 343). Ainda que novos horizontes tenham sido abertos com esta perspectiva, a noção de uma revolução ideológica voltada para o passado carrega em si ao menos duas dificuldades: em primeiro lugar, subestima o peso dos fatores econômicos; em segundo lugar, trabalha com categorias como sociedade conservadora, reacionária, cujos conteúdos remetem-se imediatamente aqueles de sociedade progressista $\mathrm{e}$ revolucionária, tal qual iremos encontrar em análises dos movimentos sociais da Revolução Francesa, 300 anos depois. Na visão de Lawrence Stone (STONE, 1970: 59; 62), não é um tipo de sistema de legitimação que está em jogo, onde ocorre a disputa entre uma Revolução Conservadora versus Revolução Progressista, mas antes a distância entre as exigências dos grupos envolvidos e as condições materiais e mentais destes mesmos grupos para que possamos minimamente recorrer a categorias como conversadora ou revolucionária. É, pois, difícil taxar a camponeses e pequeno burgueses citadinos de inimigos da modernidade. No que diz respeito às fontes, aqui também os autores patinavam em interpretações uma vez que boa parcela da documentação - editos, proclamas, regulamentos, punições etc. saíram das penas de burocratas do status quo. E a Burguesia? E Lutero? E Münzter? "Se a reforma também dificilmente foi responsável por fazer o capitalismo," diz G. Hartfiel, "muito menos o capitalismo por fazer a reforma. A Reforma não foi uma revolução burguesa primeva (..), muito mais foi uma revolta baseada em uma antiga concepção moral e de normas de comportamento de camadas tradicionais da pequena burguesia e do campesinato, que protestaram contra a 
corrupção da Igreja dominante (...)" (FISCHER, 1977: 50)4 . Lutero, pois, reduzido a um monge que prega um sacerdócio para todos (allgemeine Priestertum) (FISCHER, 1977: 80), sem intermediações. E sobre Müntzer? Um grande silencio...

c) Chegamos então a uma terceira linha de pensamento: a revolução do

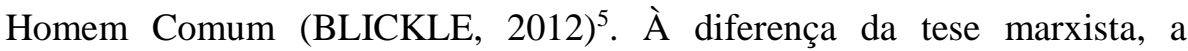
burguesia ainda não se constituía uma classe; e diversamente da tendência de oposição ideológica Conservador x Progressista, acentua-se aqui o caráter disruptivo do movimento campesino. Para tanto, parte-se de três premissas: a) uma nova sociedade e organização social como fim; b) um movimento de massa como princípio; e, a violência como meio (HOCKERTS, 1979: 14). Considerações sobre a formação do Mercado e do Capitalismo ficam em segundo plano, mas em compensação, de modo renovado, a "voz" do campesinato é ouvida e posta no centro das atenções por meio de um documento. Trata-se do "manifesto dos 12 artigos", manifesto anônimo, publicado em 1525, que traz consigo os elementos revolucionários do "direito divino". Sobre ele debruçaram-se Müntzer e Lutero. A partir dele, Burguesia, Clero e Nobreza temeram o que antes lhes era desconhecido. Nele fundem-se a doutrina teológica e o programa revolucionário para a queda das antigas ordens. Para ele convergem Lutero e Müntzer (MÜLLER, 2013).

4 "Ist die Reformation also kaum für den Kapitalismus verantwortlich zu machen, so ebensowenig der Kapitalismus für die Reformation. Die Reformation war keine frühbürgerliche Revolution (...), viel eher eine Revolte der na alten Moralvorstellungen und Verhaltensnormen hängenden bäuerlichen, kleibürgerlichen, traditionellen Schichten, die gegen die Korruption in der herrschenden Kirche und Welt protestierten".

${ }^{5}$ A designação homem comum, nas palavras do autor (BLICKLE: 2012, 45-36), refere-se aqui a uma noção mais geral. Não se trata, pois, de qualquer homem comunal ou da comuna vilã, mas antes daquele apartado da comunidade política. Assim, os protestos não se dirigem a uma determinada autoridade, a um determinado senhorio, mas antes a toda autoridade e senhorio injustos. 


\section{Figura 4}

Coleção dos camponeses da Suábia Superior 1525 (título em xilogravura dos doze artigos).

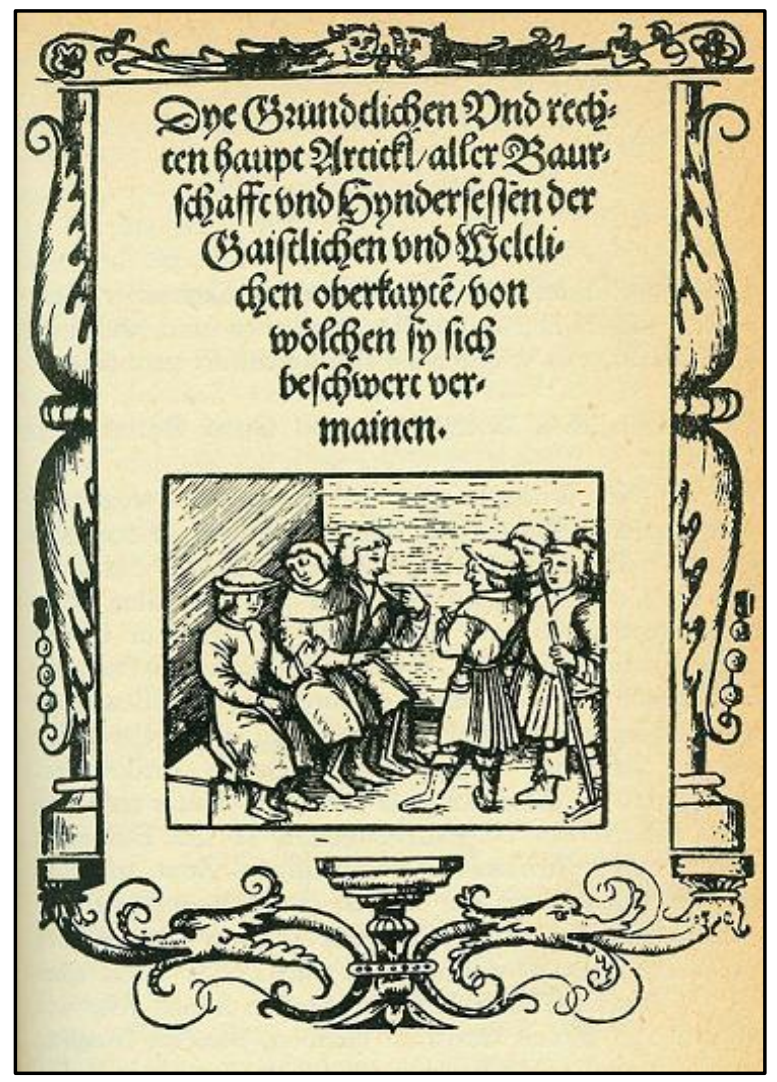

Fonte: Stadtarchiv Memmingen. Disponível em:

<https://stadtarchiv.memmingen.de/918.html>. Acesso em: 31 nov. 2018.

Dye grundtlichen vnd rechten haupt artickel, aller baurschafft vnnd hyndersessen der gaistlichen vnd weltlichen oberkayten, von wo(e)lchen sy sich beschwert vermainen ${ }^{6}$

Die grundlichen und rechten Hauptartikel aller Baurschaft und Hintersessen der geistlichen und weltlichen Oberkeiten, von wölchen sie sich beschwert vermeinen

\footnotetext{
${ }^{6}$ A tradução foi dividida em três colunas: a primeira coluna contém a forma dialetal do alemão do século XVI, a segunda foi redigida em alemão moderno, embora preservando aqui e ali expressões locais e a terceira está em língua portuguesa.
} 
Os artigos fundamentais e justos de todo o campesinato, antecedidos por aqueles relativos às autoridades espirituais e leigas, em relação às quais eles se julgam incomodados.

M cccc, quadratum, Ix et duplicatum

$V$ cum transit, christiana secta peribit ${ }^{7}$

Versammlung der oberschwäbischen Bauern 1525 (Titelholzschnitt der Zwölf Artikel)

Coleção dos camponeses da Suábia Superior 1525 (título em xilogravura dos doze $\operatorname{artigos})^{8}$

\footnotetext{
${ }^{7}$ A tradução aqui não é clara. Parece-nos uma quadra: Um autor do século XIX assim a interpreta: "Ist das Jahr 1525 um/ist's aus mit jetzigen Christentum", ou como se depreende diretamente do título da folha de rosto por meio de um circunlóquio: "Ein M (tausend), vier C (hundert), zwei L (fünfzig) darbei/ und ein X (zehn), das zwiefach sei/ bald man in V (fünf) dazu wird schreiben/ werden nit so viel Sekten der Christen bleiben".( ZIMMERMANN, $1842: 109$ ).

${ }^{8}$ Disponível em: <http://www.bauernkriege.de/artikel.html〉. Acesso em: 08 ago. 2016.
} 
Dem christlichen leeser fryd vnnd gnad gottes durch Christum.

Es seyn vil wider christen, die yetzund von ween der versammleten baurschafft das euangelion $\mathrm{zu}(\mathrm{o})$ schmehen vrsach nehmen, sagent, das seyn die frücht des newen euangelions? Nyemant gehorsam seyn, an allen ortten sich empor heben vnd auff po(e)men, mit grossem gewalt zu(o)hauff lauffen vnd sich rotten, gaistlich vnnd weltliche oberkaiten zu(o)reformieren, außzu(o)reytten, ja villeücht gar zu(o) erschlagen?

Allen disen gotlosen freuenlichen vrtailern antwurten diese nachgeschribne artickel, Am ersten das sye dise schmach des wort gotes auffheben, $\mathrm{zu}(\mathrm{o}) \mathrm{m}$ andern die vngehorsamikait, ja die empo(e)rung aller bauren christenlich endtschuldigen. $\mathrm{Zu}(\mathrm{o}) \mathrm{m}$ ersten, ist das euangelion nit ain vrsach der empo(e)rungen oder auffru(o)ren, dye weyl es ain rede ist, von Christo, dem verhaissne Messia, welchs wort vnd leben nichts dann liebe, fride, geduldt vnd ainigkaiten lernet. Also das alle die in disen Christum glauben, lieplich, fridlich, gedultig vnd ainig werden. So dann der grund aller artickel der bawren (wie dann klar gesehen wirt), das euangelion $\mathrm{zu}(\mathrm{o}) \mathrm{ho}(\mathrm{e}) \mathrm{ren}$ vnd dem gemeß zu(o) leben, dahin gericht ist. Wie mügen dann die widerchristen das ewangelion ain ursach der embo(e)rung vnd des vngehorsams nennen? Das aber ettlich widerchristen
Dem christlichen Leser Fried und Gnad Gottes durch Christum.

Es sein viel Widerchristen, die jetzund von wegen der versammleten Baurschaft, das Evangelion zu schmehen Ursach nehmen, sagent: Das sein die Frucht des neuen Evangelions? Niemand gehorsam sein, an allen Orten sich emporheben und aufbömen, mit großem Gewalt zuhauflaufen und sich rotten, geistlich und weltliche Oberkeiten zu reformieren, auszureuten, ja vielleucht gar zu erschlagen? Allen diesen gottlosen, frevenlichen Urteilern antwurten diese nachgeschriebne Artikel. Am ersten, daß sie diese Schmach des Wort Gottes aufheben, zum andern die Ungehorsamigkeit, ja die Empörung aller Bauren christenlich entschuldigen. Zum ersten ist das Evangelion nit ein Ursach der Empörungen oder Aufruhren, dieweil es ein Rede ist von Christo dem verheißne Messia, welchs Wort und Leben nichts dann Liebe, Friede, Geduld und Einigkeiten lernet. Also daß alle, die in diesen Christum glauben, lieblich, friedlich, geduldig und einig werden. So dann der Grund aller Artikel der Bauren (wie dann klar gesehen wird) das Evangelion zu hören und demgemeß zu leben dahin gericht ist. Wie mügen dann die Widerchristen das

Evangelion ein Ursach der Empörung und des Ungehorsams nennen? Daß aber etlich Widerchristen und Feind des Evangelii wider
Ao leitor cristão, Paz e Graça de Deus por Cristo.

Existem muitos anti-cristãos que, por causa das reuniões dos camponeses, aproveitam a ocasião para desdenhar os Evangelhos dizendo: isto é acaso o fruto do novo Evangelho? Que ninguém tenha que obedecer e que todos, em todos os lugares, devem levantar-se em revoltas e sublevar-se para reformar, talvez para destruir completamente as autoridades, tanto espirituais como seculares? A todos estes acusadores sem Deus respondem os artigos mais abaixo expostos primeiro para refutar estas reprovações a palavra de Deus, logo para desculpar cristianamente a desobediência e inclusive a revolta de todo o campesinato. Em primeiro lugar, o Evangelho não é causa de revoltas, nem de desordem, porquanto é a palavra de Cristo, o Messias prometido, a Palavra da vida, que não ensina nada senão amor, paz, paciência e concordia. Assim, todos aqueles que crêem em Cristo devem aprender a ser plenos de afeto, pacíficos, harmoniosos e a suportar o sofrimento. Portanto, o fundamento de todos os artigos dos campesinos (como será seguidamente demonstrado) é a aceitação e a vida de conformidade com o Evangelho.

Como podem esses anticristãos afirmar que o Evangelho é a causa da revolta e de desobediência? $\mathrm{O}$ [fato] que esses anti- 


\begin{tabular}{|c|c|c|}
\hline $\begin{array}{l}\text { vnd feynd deß euangelij } \\
\text { wider so(e)lliche } \\
\text { anmu(o)ttung vnd begerung } \\
\text { sich lonen vnd auffbo(e)men, } \\
\text { ist das euangelion nit vr- } \\
\text { sach, sonder der teüfel, der } \\
\text { schedlichst feynd deß } \\
\text { ewangelij, der solches durch } \\
\text { den vnglauben in den seynen } \\
\text { erweckt. Hye mitte das, das } \\
\text { wort gotes (liebe, fryd, vnd } \\
\text { ainigkait lernent) } \\
\text { vndergetruckt vnd } \\
\text { wegkgenommen wurde. ॥ } \\
\text { Zu(o)m andern dann klar } \\
\text { lauter volget, das dye bawren } \\
\text { in jren artickeln solches } \\
\text { euangelion zu(o)r leer vnd } \\
\text { leben begerendt, nit mügen } \\
\text { vngehorsam, auffru(e)risch } \\
\text { genennt werden. Ob aber got } \\
\text { die pauren (nach seynem } \\
\text { wort zu(o) leben a(e)ngstlich } \\
\text { ru(o)ffent) erho(e)ren will, } \\
\text { wer will den willen gotes } \\
\text { tadlen? Wer will in sein } \\
\text { gericht greyffen? Ja wer will } \\
\text { seiner mayestet } \\
\text { wyderstreben? Hat er die } \\
\text { kinder Israhel, zu(o) jm } \\
\text { schreyendt, erho(e)ret vnd } \\
\text { auß der hand pharaonis } \\
\text { erlediget? Mag er nit noch } \\
\text { heut die seynen erretten? Ja, } \\
\text { er wirts erretten! Vnd in } \\
\text { ainer kürtz! Derhalben } \\
\text { christlicher leser, solliche } \\
\text { nachvolgendt artickel lyse } \\
\text { mit fleyß, vnd nach mals } \\
\text { vrtail. ॥ }\end{array}$ & $\begin{array}{l}\text { söliche Anmutung und } \\
\text { Begehrung sich löhnen und } \\
\text { aufbömen, ist das Evangelion } \\
\text { nit Ursach, sonder der } \\
\text { Teufel, der schedlichst Feind } \\
\text { des Evangelii, der solches } \\
\text { durch den Unglauben in den } \\
\text { Seinen erweckt, hiemitte daß } \\
\text { das Wort Gottes (Liebe, } \\
\text { Fried und Einigkeit lernend) } \\
\text { untergedruckt und } \\
\text { weggenommen wurde. } \\
\text { Zum andern dann klar lauter } \\
\text { folget, daß die Bauren in } \\
\text { ihren Artikeln solches } \\
\text { Evangelion zur Lehr und } \\
\text { Leben begehrent, nit mügen } \\
\text { ungehorsam, aufrührisch } \\
\text { genennt werden. Ob aber } \\
\text { Gott die Bauren (nach } \\
\text { seinem Wort zu leben } \\
\text { ängstlich rufend) erhören } \\
\text { will, wer will den Willen } \\
\text { Gottes tadlen? Wer will in } \\
\text { sein Gericht greifen? Ja wer } \\
\text { will seiner Majestet } \\
\text { widerstreben? Hat er die } \\
\text { Kinder Israhel zu im } \\
\text { schreiend erhöret und aus der } \\
\text { Hand Pharaonis erlediget, } \\
\text { mag er nit noch heut die } \\
\text { Seinen erretten? Ja, er wirds } \\
\text { erretten! Und in einer Kürtz! } \\
\text { Derhalben, christlicher Leser, } \\
\text { soliche nachfolgend Artikel } \\
\text { liese mit Fleiß und nachmals } \\
\text { urteil. }\end{array}$ & $\begin{array}{l}\text { cristãos e inimigos do } \\
\text { Evangelho se oponham eles } \\
\text { mesmos a estes } \\
\text { requerimentos, se deve, não } \\
\text { ao Evangelho, senão ao } \\
\text { Diabo, o pior inimigo do } \\
\text { Evangelho, que provoca tal } \\
\text { oposição semeando a dúvida } \\
\text { na mente de seus seguidores } \\
\text { e dessa maneira, a palavra de } \\
\text { Deus, que ensina amor, paz e } \\
\text { concordia, é apartada. Em } \\
\text { segundo lugar, está claro que } \\
\text { os campesinos solicitam que } \\
\text { o Evangelho lhes seja } \\
\text { ensinado como guia de vida e } \\
\text { não podem ser chamados } \\
\text { desobedientes ou como } \\
\text { reacionários à ordem. Que } \\
\text { Deus conceda ou não aos } \\
\text { camponeses (ansiosos de } \\
\text { viver conforme a sua } \\
\text { palavra) a realização de suas } \\
\text { petições, quem encontrará } \\
\text { uma falta na vontade do } \\
\text { Altíssimo? Quem interferirá } \\
\text { no seu juízo, que se oporá a } \\
\text { sua majestade? Não escutou } \\
\text { por acaso aos filhos de Israel, } \\
\text { quando o invocaram e os } \\
\text { resgatou da mão do Faraó? } \\
\text { Não pode Ele, hoje mesmo, } \\
\text { salvar os seus? Sim, Ele os } \\
\text { salvará e em verdade } \\
\text { rapidamente. Em } \\
\text { consequência, oh leitor } \\
\text { cristão, leia com zelo os } \\
\text { seguintes artigos e os julgue } \\
\text { uma outra vez. }\end{array}$ \\
\hline $\begin{array}{l}\text { Hye nachvolgent die } \\
\text { artickel. }\end{array}$ & & Aqui seguem os artigos \\
\hline
\end{tabular}




\begin{tabular}{|c|c|c|}
\hline $\begin{array}{l}\text { Der erst artickel: } \\
\text { Zum ersten ist vnser } \\
\text { diemu(e)ttig bytt vnd beger, } \\
\text { auch vnser aller will vnd } \\
\text { maynung, das wir nun } \\
\text { fürohin gewalt vnd macht } \\
\text { wo(e)llen haben, ain gantze } \\
\text { gemain sol ain pfarer selbs } \\
\text { erwo(e)len vnd kyesen. Auch } \\
\text { gewalt haben, den selbigen } \\
\text { wider zu(o)entsetzen, wann } \\
\text { er sich vngepürlich hieldt. } \\
\text { Der selbig erwo(e)lt pfarrer } \\
\text { soll vns das hailig euangeli } \\
\text { lauter vnd klar predigen one } \\
\text { allen menschlichen zu(o)satz, } \\
\text { leer vnd gebot, dann vns den } \\
\text { waren glauben stetz } \\
\text { verkündigen, geyt vns ain } \\
\text { vrsach got vnd sein gnad } \\
\text { zu(o) bitten, vnns den } \\
\text { selbygen waren glawben } \\
\text { einbylden vnd in vns } \\
\text { bestetten. Dann wann seyn } \\
\text { genad in vnß nit eingepyldet } \\
\text { wirdt, so bleyben wir stetz } \\
\text { fleysch vnd blu(o)t, das dann } \\
\text { nichts nutz ist, wie } \\
\text { kla(e)rlich in der geschrifft } \\
\text { stat, das wir allain durch den } \\
\text { waren glauben zu(o) got } \\
\text { kommen kinden, vnd allain } \\
\text { durch seyn barmhertzigkait } \\
\text { sa(e)lig mu(e)ssen werden. } \\
\text { Darumb ist vns ain } \\
\text { so(e)llicher vorgeer vnd } \\
\text { pfarrer von no(e)tten, vnd in } \\
\text { dieser gestalt in der } \\
\text { geschrifft gegrindt. }\end{array}$ & $\begin{array}{l}\text { Der erst Artikel. } \\
\text { Zum ersten ist unser } \\
\text { diemütig Bitt und Begehr } \\
\text { auch unser aller Will und } \\
\text { Meinung, daß wir nun } \\
\text { fürohin Gewalt und Macht } \\
\text { wöllen haben, ein ganze } \\
\text { Gemein soll ein Pfarrer selbs } \\
\text { erwöhlen und kiesen, auch } \\
\text { Gewalt haben, denselbigen } \\
\text { wieder zu entsetzen, wann er } \\
\text { sich ungebührlich hielt. } \\
\text { Derselbig erwöhlt Pfarrer } \\
\text { soll uns das heilig Evangeli } \\
\text { lauter und klar predigen ohne } \\
\text { allen menschlichen Zusatz, } \\
\text { Lehr und Gebot. Dann uns } \\
\text { den wahren Glauben stets } \\
\text { verkündigen, geit uns ein } \\
\text { Ursach, Gott um sein Gnad } \\
\text { zu bitten, uns denselbigen } \\
\text { wahren Glauben einbilden } \\
\text { und in uns besteten; dann } \\
\text { wann sein Genad in uns nit } \\
\text { eingebildet wird, so bleiben } \\
\text { wir stets Fleisch und Blut, } \\
\text { das dann nichts nutz ist, wie } \\
\text { klärlich in der Geschrift stat, } \\
\text { daß wir allein durch den } \\
\text { wahren Glauben zu Gott } \\
\text { kommen kinden und allein } \\
\text { durch sein Barmherzigkeit } \\
\text { sälig müssen werden. Darum } \\
\text { ist uns ein sölicher Vorgeher } \\
\text { und Pfarrer vonnöten und in } \\
\text { dieser Gestalt in der } \\
\text { Geschrift gegrindt. }\end{array}$ & $\begin{array}{l}\text { O primeiro artigo. } \\
\text { Primeiramente, é nossa } \\
\text { humilde petição e rogo, } \\
\text { assim como nossa vontade e } \\
\text { resolução que de hoje em } \\
\text { diante tenhamos poder e } \\
\text { autoridade de tal maneira que } \\
\text { cada comunidade possa } \\
\text { eleger e nomear um pastor. } \\
\text { Que tenhamos também o } \\
\text { direito de depô-lo no caso de } \\
\text { conduta inapropriada. Este } \\
\text { mesmo pastor eleito nos } \\
\text { ensinará o Santo Evangelho } \\
\text { pura e simplesmente, sem } \\
\text { nenhum agregado, doutrina } \\
\text { ou mandamento elaborado } \\
\text { pelo homem. Porquanto o } \\
\text { ensino continuo da Fé } \\
\text { verdadeira nos conduzirá a } \\
\text { implorar a Deus que, através } \\
\text { de sua Graça, a Fé cresça } \\
\text { dentro de nós e chegue a ser } \\
\text { parte integrante de nós. Pois } \\
\text { se sua Graça não obra em } \\
\text { nós, permaneceremos para } \\
\text { sempre na carne e no sangue, } \\
\text { o que equivale a nada, já que } \\
\text { a Escritura claramente ensina } \\
\text { que só através da Fé } \\
\text { verdadeira chegaremos a } \\
\text { Deus. Só através de sua } \\
\text { Graça poderemos alcançar a } \\
\text { gloriosa misericórdia. Por } \\
\text { isso, um guia e um pastor é } \\
\text { necessário e na maneira } \\
\text { descrita está fundado nas } \\
\text { Escrituras. }\end{array}$ \\
\hline
\end{tabular}




\begin{tabular}{|c|c|c|}
\hline $\begin{array}{l}\text { Der ander artickel: } \\
\text { Zu(o)m andern, nach dem } \\
\text { der recht zehat auff gesetzt } \\
\text { ist im alten testament vnd im } \\
\text { neuen als erfüldt, nichts } \\
\text { destminder wo(e)llen wir den } \\
\text { rechten korn zehat gern } \\
\text { geben, doch wie sich gebürt. } \\
\text { Dem nach man sol in got } \\
\text { geben vnd den seynen } \\
\text { mitaylen, gebürt es ainem } \\
\text { pfarrer, so klar das wort gots } \\
\text { verkindt. Seyen wir des } \\
\text { willen hinfüro disen zehat } \\
\text { vnser kirch bro(e)pst, so dan } \\
\text { ain gemain setzt, } \| \text { sollen } \\
\text { einsemlen vnd eynnemen, } \\
\text { daruon ainem pfarrer, so von } \\
\text { ainer gantzen gemain } \\
\text { erwo(e)lt wirt, seyn zymlich } \\
\text { gnu(o)gsam auffenthalt } \\
\text { geben, jm vnd den seynen, } \\
\text { nach erkantnus ainer gantzen } \\
\text { gmain. Vnnd was über bleybt } \\
\text { sol man (armen dürfftigen, so } \\
\text { im selben dorff verhanden } \\
\text { seynd) mittailen, nach gestalt } \\
\text { der sach vnd erkantnus ainer } \\
\text { gemain. Was über bleybt, } \\
\text { soll man behaltten, ob man } \\
\text { raysen mu(e)ßt von lands not } \\
\text { wegen. Darmit man kain } \\
\text { landts steüer dürff auff den } \\
\text { armen man legen, sol manß } \\
\text { von disem überschuß } \\
\text { außrichten. Auch ob sach } \\
\text { were, daz ains oder mer } \\
\text { do(e)rffer weren, die den } \\
\text { zehenden selbs verkaufft } \\
\text { hettent auß ettlicher not } \\
\text { halben, die selbigen so } \\
\text { darumb zu(o) zaigen, in der } \\
\text { gestalt haben von aynem } \\
\text { gantzen dorff, der sol es nit } \\
\text { entgelten, sonder wir wellen } \\
\text { vns zymmlicher weyß nach } \\
\text { gestalt und sach mit im } \\
\text { vergleychen, jm sollichs } \\
\text { wider mit zymlicher zyl vnd } \\
\text { zeyt ablassen. Aber wer von } \\
\text { kainem dorff sollichs } \\
\text { erkaufft hat vnd jre forfaren } \\
\text { jnen selbs solchs } \\
\text { zu(o)geaygent haben, } \\
\text { wo(e)llen vnd solen vnd }\end{array}$ & $\begin{array}{l}\text { Der ander Artikel. } \\
\text { Zum andern. Nachdem der } \\
\text { recht Zehnt aufgesetzt ist im } \\
\text { Alten Testament und im } \\
\text { Neuen alles erfüllt, nichts } \\
\text { destminder wollen wir den } \\
\text { rechten Kornzehnt gern } \\
\text { geben, doch wie sich } \\
\text { gebührt: Demnach man soll } \\
\text { ihn Gott geben und den } \\
\text { Seinen mitteilen. Gebührt es } \\
\text { einem Pfarrer, so klar das } \\
\text { Wort Gotts verkindt, seien } \\
\text { wir des Willen hinfüro, } \\
\text { diesen Zehnt unser Kirch } \\
\text { Pröpst, so dann ein Gemein } \\
\text { setzt, sollen einsammlen und } \\
\text { einnehmen, darvon einem } \\
\text { Pfarrer, so von einer ganzen } \\
\text { Gemein erwöhlt wird, sein } \\
\text { ziemlich gnugsam Aufenthalt } \\
\text { geben, ihm und den Seinen, } \\
\text { nach Erkanntnus einer } \\
\text { ganzen Gemein, und was } \\
\text { überbleibt, soll man armen } \\
\text { Dürftigen, so im selben Dorf } \\
\text { verhanden seind, mitteilen, } \\
\text { nach Gestalt der Sach und } \\
\text { Erkanntnus einer Gemein. } \\
\text { Was überbleibt, soll man } \\
\text { behalten, ob man Reisen } \\
\text { müßt von Lands Not wegen. } \\
\text { Darmit man kein Lands } \\
\text { Steuer dürf auf den armen } \\
\text { Mann legen, soll mans von } \\
\text { diesem Überschuß } \\
\text { ausrichten. Auch ob Sach } \\
\text { were, daß eins oder mehr } \\
\text { Dörfer weren, die den } \\
\text { Zehenten selbs verkauft } \\
\text { hettent aus etlicher Not } \\
\text { halben, dieselbigen, so } \\
\text { darum zu zeigen, ihn } \\
\text { dergestalt haben von einem } \\
\text { ganzen Dorf, der soll es nit } \\
\text { entgelten, sonder wir wellen } \\
\text { uns ziemlicher Weis nach } \\
\text { Gestalt der Sach mit ihm } \\
\text { vergleichen, ihm solichs } \\
\text { wieder mit ziemlicher Ziel } \\
\text { und Zeit ablösen. Aber wer } \\
\text { erkauft heinem Dorf solichs } \\
\text { Vorfahren ind ihre } \\
\text { zugeeigent haben, wöllen }\end{array}$ & $\begin{array}{l}\text { O segundo artigo. Em } \\
\text { segundo lugar, assim como } \\
\text { um justo dízimo está } \\
\text { estabelecido pelo Antigo } \\
\text { Testamento e confirmado no } \\
\text { Novo [Testamento], nós } \\
\text { estamos dispostos e } \\
\text { desejosos de pagar o justo } \\
\text { dízimo de grão. A palavra de } \\
\text { Deus estabeleceu que dar } \\
\text { está em conformidade a Deus } \\
\text { e que na distribuição aos } \\
\text { seus, os serviços de um } \\
\text { pastor são requeridos. } \\
\text { Queremos que no futuro, } \\
\text { quem quer que seja o } \\
\text { preboste eclesiástico } \\
\text { designado pela comunidade, } \\
\text { ele recolherá e receberá este } \\
\text { dízimo. Deste dízimo, } \\
\text { proverá ao pastor eleito por } \\
\text { toda a comunidade uma } \\
\text { subsistência decente e } \\
\text { suficiente, com o justo } \\
\text { parecer (ou com o } \\
\text { conhecimento) da } \\
\text { comunidade em sua } \\
\text { totalidade. O remanescente } \\
\text { eventual será distribuído } \\
\text { entre os pobres do lugar, } \\
\text { segundo o exijam as } \\
\text { circunstâncias e a opinião } \\
\text { geral. Se ainda restar um } \\
\text { pouco, será guardado por } \\
\text { alguém que tenha que } \\
\text { abandonar o país por causa } \\
\text { da pobreza. Far-se-á também } \\
\text { provisão deste excedente } \\
\text { para evitar que se agrave (?) } \\
\text { com impostos a terra aos } \\
\text { pobres. No caso de que um } \\
\text { ou mais povos se tenham } \\
\text { comprometido } \\
\text { voluntariamente a pagar o } \\
\text { dízimo em razão da penúria e } \\
\text { que cada povo tenha tomado } \\
\text { essas medidas de maneira } \\
\text { coletiva, o adquirente não } \\
\text { sofrerá perdas, mas queremos } \\
\text { que se chegue a um acordo } \\
\text { apropriado para o reembolso } \\
\text { da soma mais o investimento } \\
\text { devido pelo povo. Mas a } \\
\text { aqueles que tenham } \\
\text { adquirido direito a dízimos, }\end{array}$ \\
\hline
\end{tabular}




\begin{tabular}{|l|l|l|}
\hline seynd jnen nichts weyters & und sollen und seind ihnen & não mediante a compra, \\
schuldig zu(o)geben, alain & nichts weiters schuldig zu & senão mediante apropriação \\
wie obstat vnsern erwo(e)lten & geben, allein, wie ob stat, & pela obra de seus ancestrais, \\
pfarrer darmit zu(o) & unsern erwöhlten Pfarrer & não os será nem os deverá \\
vnderhalten, nachmalen & darmit zu unterhalten, & pagar soma alguma de agora \\
ablesen oder den dürfftigen & nachmalen ablösen oder den & em diante. O povo deverá \\
mittailen, wie die hailig & Dürftigen mitteilen, wie die & aplicar o pagamento do \\
geschryfft innho(e)lt, sy & Heilig Geschrift inhölt, sie & dízimo para a manutenção do \\
seyen gaistlich oder & seien geistlich oder weltlich. & pastor, eleito como se \\
welttlich. Den klaynen zehat & Den kleinen Zehnt wöllen & indicou mais acima, ou para \\
wo(e)llen wir gar nit geben. & wir gar nit geben, dann Gott & o consolo dos pobres, como \\
Dann got der herr das vich & der Herr hat das Viech frei & assim [o] ensina a Escritura. \\
frey dem menschen & dem Menschen beschaffen, & Quanto ao dízimo miúdo, \\
beschaffen, das wir für ain & das wir für ein unziemlichen & seja eclesiástico ou laico, não \\
vnzymlichen zehat schetzen, & Zehnt schetzen, den die & será pago a partir de agora, \\
den die menschen erdicht & Menschen erdicht haben. & porquanto o Senhor Deus \\
criou o ganho para sua livre \\
haben. Darumb wo(e)llen wir & Darum wöllen wir ihn nit & utilização para o homem. Em \\
jn nit weytter geben. & weiter geben. & consequência, não \\
& & pagaremos no que se segue \\
& & este indecoroso dízimo de \\
pura criação humana.
\end{tabular}




\begin{tabular}{|c|c|c|}
\hline & $\begin{array}{l}\text { Der dritt Artikel. } \\
\text { Zum dritten ist der Brauch } \\
\text { bisher gewesen, daß man uns } \\
\text { für ihr eigen Leut gehalten } \\
\text { haben, wölchs zu erbarmen } \\
\text { ist, angesehen, daß uns } \\
\text { Christus all mit seinem } \\
\text { kostbarlichen Blutvergüßen } \\
\text { erlöst und erkauft hat, den } \\
\text { Hirten gleich als wohl als } \\
\text { den Höchsten, kein } \\
\text { ausgenommen. } \\
\text { Darum erfindt sich mit der } \\
\text { Geschrift, daß wir frei seien } \\
\text { und wöllen sein. } \\
\text { Nit daß wir gar frei wollen } \\
\text { sein, kein Oberkeit haben } \\
\text { wellen, lernet uns Gott nit. } \\
\text { Wir sollen in Geboten leben, } \\
\text { nit in freiem fleischlichen } \\
\text { Mutwillen, sonder Gott } \\
\text { lieben, ihn als unsern Herren } \\
\text { in unsern Nechsten erkennen } \\
\text { und alles das ton, so wir auch } \\
\text { gern hetten, das uns Gott am } \\
\text { Nachtmahl geboten hat zu } \\
\text { einer Letz. Darum sollen wir } \\
\text { nach seinem Gebot leben. } \\
\text { Zeigt und weist uns dies } \\
\text { Gebot an, daß wir der } \\
\text { Oberkeit nit ghorsam seien? } \\
\text { Nit allein der Oberkeit, } \\
\text { sunder wir sollen uns gegen } \\
\text { jedermann diemütigen, daß } \\
\text { wir auch gehren gegen unser } \\
\text { erwehlten und gesetzten } \\
\text { Oberkeit (so uns von Gott } \\
\text { gesetzt) in allen ziemlichen } \\
\text { und christlichen Sachen gern } \\
\text { gehorsam sein. Seien auch } \\
\text { ohn Zweifel, ihr werdent uns } \\
\text { der Eigenschaft als wahr und } \\
\text { recht Christen gern entlassen } \\
\text { oder uns im Evangeli des } \\
\text { berichten, daß wirs seien. } \\
\end{array}$ & $\begin{array}{l}\text { O terceiro artigo. Em } \\
\text { terceiro, tem sido até agora } \\
\text { costume para alguns de } \\
\text { tratar-nos como se fôssemos } \\
\text { de sua propriedade privada, o } \\
\text { que é de se lamentar, } \\
\text { considerando que Cristo nos } \\
\text { libertou e redimiu a todos por } \\
\text { igual, ao servo e ao Senhor, } \\
\text { sem exceção, por meio do } \\
\text { derramamento de seu } \\
\text { precioso sangue. Assim, } \\
\text { conforme a Escritura somo e } \\
\text { queremos ser livres. Isto não } \\
\text { significa que desejamos ser } \\
\text { absolutamente livres e não } \\
\text { estar sujeito a alguma } \\
\text { autoridade. Deus não nos } \\
\text { ensina que devemos levar } \\
\text { uma vida desordenada nos } \\
\text { prazeres da carne, senão que } \\
\text { teremos que amar a Deus, } \\
\text { nosso Senhor, e a nosso } \\
\text { próximo. Nós nos } \\
\text { conformaremos com alegria } \\
\text { a todo isto, como Deus nos } \\
\text { ordenou na celebração da } \\
\text { comunhão. Não nos ordenou } \\
\text { desobedecer às autoridades, } \\
\text { senão antes praticar a } \\
\text { humildade, não só com } \\
\text { aqueles que exercem a } \\
\text { autoridade, senão com todos. } \\
\text { Nós estamos assim dispostos } \\
\text { a prestar obediência a nossas } \\
\text { autoridades, eleitas e } \\
\text { regulares, em todas as coisas } \\
\text { próprias que concernem a um } \\
\text { cristão. Damos, pois, por } \\
\text { aceito que Vós nos libertareis } \\
\text { da servidão como cristãos } \\
\text { verdadeiros, a menos que se } \\
\text { nos demonstre que do } \\
\text { Evangelho surja } \backslash \text { apareça } \\
\text { que devamos ser servos. }\end{array}$ \\
\hline
\end{tabular}




\begin{tabular}{|c|c|c|}
\hline $\begin{array}{l}\text { Der viert artickel: } \\
\text { Zum vierten ist bißher jm } \\
\text { brauch gewesen, daß kayn } \\
\text { armer man nit gewalt gehabt } \\
\text { hatt, das willpret, gefigel } \\
\text { oder fisch jn fliessenden } \\
\text { wasser nit zu(o) fachen zu(o) } \\
\text { gelassen werden, welchs vns } \\
\text { gantz vnzymlich vnd } \\
\text { vnbru(e)derlich dunckt, } \\
\text { sunder aigennützig vnd dem } \\
\text { wort gotz nit gemeß sein. } \\
\text { Auch in etlichen ortern die } \\
\text { oberkait vns das gewild zu(o) } \\
\text { trutz vnd mechtigem schaden } \\
\text { haben, wil vns das vnser (so } \\
\text { got dem menschen zu(o) nutz } \\
\text { wachsen hat lassen) die } \\
\text { vnuernüfftigen thyer zu(o) } \\
\text { vnutz verfretzen } \\
\text { mu(e)twiligklich (leyden } \\
\text { mu(e)ssen) dar zu(o) } \\
\text { stillschweigen, das wider } \\
\text { gott vnd dem nechsten ist, } \\
\text { Wann als gott der herr den } \\
\text { menschen erschu(o)ff, hat er } \\
\text { jm gewalt geben vber alle } \\
\text { thier, vber den fogel im lufft } \\
\text { vnd vber den fisch jm } \\
\text { wasser. Darumb ist vnser } \\
\text { begeren, wann ainer wasser } \\
\text { hette, das ers mit } \\
\text { gnu(o)gsamer schriff be- } \| \\
\text { weysen mag, das man das } \\
\text { wasser vnwyssenlych also } \\
\text { erkaufft hette, begeren wir } \\
\text { jms nit mit gewalt zu(o) } \\
\text { nemen. Sunder man mu(e)st } \\
\text { ain christlich eynsechen } \\
\text { darynnen haben von wegen } \\
\text { bru(o)derlicher lieb, aber wer } \\
\text { nit gnu(e)gsam anzaigen } \\
\text { darumb kann thon, solß ainer } \\
\text { gemayn zymlicher weyß } \\
\text { mittailen. }\end{array}$ & $\begin{array}{l}\text { Der viert Artikel. } \\
\text { Zum vierten ist bisher im } \\
\text { Brauch gewesen, daß kein } \\
\text { armer Mann nit Gewalt } \\
\text { gehabt hat, das Wildbret, } \\
\text { Gevigel oder Fisch in } \\
\text { fliessenden Wasser nit zu } \\
\text { fachen zugelassen werden, } \\
\text { welchs uns ganz unziemlich } \\
\text { und unbrüderlich dunkt, } \\
\text { sunder eigennützig und dem } \\
\text { Wort Gotts nit gemeß sein. } \\
\text { Auch in etlichen Ortern die } \\
\text { Oberkeit uns das Gewild zu } \\
\text { Trutz und mechtigem } \\
\text { Schaden haben, wir uns das } \\
\text { unser (so Gott dem } \\
\text { Menschen zu Nutz wachsen } \\
\text { hat lassen) die } \\
\text { unvernünftigen Tier zu } \\
\text { Unnutz verfretzen } \\
\text { mutwilliglich leiden müssen, } \\
\text { darzu stillschweigen, das } \\
\text { wider Gott und dem } \\
\text { Nechsten ist; wann als Gott } \\
\text { der Herr den Menschen } \\
\text { erschuf, hat er ihm Gewalt } \\
\text { geben über alle Tier, über } \\
\text { den Vogel im Luft und über } \\
\text { den Fisch im Wasser. Darum } \\
\text { ist unser Begehren: Wann } \\
\text { einer Wasser hette, daß ers } \\
\text { mit gnugsamer Schrift } \\
\text { beweisen mag, daß man das } \\
\text { Wasser ihn wissenlich also } \\
\text { erkauft hette, begehren wir } \\
\text { ihms nit mit Gewalt zu } \\
\text { nehmen, sunder man müßt } \\
\text { ein christlich Einsehen } \\
\text { darinnen haben vonwegen } \\
\text { brüderlicher Lieb. Aber wer } \\
\text { nit gnugsam Anzeigen darum } \\
\text { kann ton, solls einer Gemein } \\
\text { ziemlicher Weis mitteilen. }\end{array}$ & $\begin{array}{l}\text { O quarto artigo. Em quarto } \\
\text { lugar, tem sido até agora } \\
\text { costume que a nenhum } \\
\text { homem pobre era permitido } \\
\text { capturar veados ou animais } \\
\text { selvagens ou peixes das } \\
\text { águas fluviais, o que nos } \\
\text { parece não apenas totalmente } \\
\text { indecoroso e pouco fraternal, } \\
\text { senão também egoísta e } \\
\text { contrário a palavra de Deus. } \\
\text { Também em alguns lugares, } \\
\text { os Superiores conservam } \\
\text { suas presas de caça para } \\
\text { nosso desgosto \dissabor e } \\
\text { grandes perdas, permitindo } \\
\text { sem nenhuma consideração } \backslash \\
\text { respeito que animais } \\
\text { selvagens destruam nossos } \\
\text { cultivos, que o Senhor se } \\
\text { esforça por fazer germinar } \\
\text { par ao uso do homem e ainda } \\
\text { devemos sofrê-lo em } \\
\text { silêncio. Tudo isto é } \\
\text { contrário a Deus e ao } \\
\text { próximo. Deus ao criar o } \\
\text { Homem deu o domínio sobre } \\
\text { todos os animais, sobre as } \\
\text { aves no ar e sobre o peixe na } \\
\text { água. Em conformidade, é } \\
\text { nosso desejo que se um } \\
\text { homem tem posse sobre } \\
\text { águas, que prove com } \\
\text { documentos suficientes que } \\
\text { tem adquirido esse direito } \\
\text { inadvertidamente por meio } \\
\text { de uma compra. Nós não } \\
\text { queremos a arrebatar-lhe por } \\
\text { meio da força, mas seus } \\
\text { direitos devem ser exercidos } \\
\text { de uma maneira fraternal e } \\
\text { cristã. Mas quem quer não } \\
\text { possa aduzir tal prova, } \\
\text { deverá desistir com boa } \\
\text { vontade de sua pretensão. }\end{array}$ \\
\hline
\end{tabular}




\begin{tabular}{|c|c|c|}
\hline $\begin{array}{l}\text { Der funfft artickel: } \\
\text { Zum fünfften seyen wir auch } \\
\text { beschwert der beholtzung } \\
\text { halb. Dann vnsere } \\
\text { herschafften habend jnenn } \\
\text { die ho(e)ltzer alle allain } \\
\text { geaignet, vnd wann der arm } \\
\text { man was bedarff, mu(o)ß ers } \\
\text { vmb zway geldt kauffen. Ist } \\
\text { vnnser maynung: Was für } \\
\text { ho(e)ltzer seyen, es habens } \\
\text { geistlich oder weltlich, jnnen, } \\
\text { die es nit erkaufft haben, } \\
\text { sollen ayner gantzen gemain } \\
\text { wider anhaim fallen, vnd } \\
\text { ainer gemayn zimlicher weiß } \\
\text { frey sein, aim yetlichen sein } \\
\text { noturfft jnß hauß zu(o) } \\
\text { brenen vmb sunst lassen } \\
\text { nehmen, auch wann von } \\
\text { no(e)ten sein wurde zu(o) } \\
\text { zymmern auch vmb sunst } \\
\text { nemen, doch mit wissen der, } \\
\text { so von der gemain darzu(o) } \\
\text { erwelt werden. So aber kains } \\
\text { verhanden wer, dann das, so } \\
\text { redlich erkaufft ist wordenn, } \\
\text { sol man sich mit den selbigen } \\
\text { briederlich vnd christelich } \\
\text { vergleichen. Wann aber das } \\
\text { gu(o)t am anfang auß inen } \\
\text { selbs geaygnet wer worden } \\
\text { vnd nachmals verkaufft } \\
\text { worden, sol man sich } \\
\text { vergleichen nach gestalt der } \\
\text { sach vnd erkantnuß } \\
\text { briederlicher lieb vnd } \\
\text { heiliger geschrifft. }\end{array}$ & $\begin{array}{l}\text { Der fünft Artikel. } \\
\text { Zum fünften seien wir auch } \\
\text { beschwert der Holzung halb, } \\
\text { dann unsere Herrschaften } \\
\text { habent ihnen die Hölzer alle } \\
\text { allein geeignet, und wann der } \\
\text { arm Mann was bedarf, muß } \\
\text { ers um zwei Geld kaufen. Ist } \\
\text { unser Meinung: Was für } \\
\text { Hölzer seien, es habens } \\
\text { Geistlich oder Weltlich } \\
\text { innen, die es nit erkauft } \\
\text { haben, sollen einer ganzen } \\
\text { Gemein wieder anheimfallen } \\
\text { und einer Gemein ziemlicher } \\
\text { Weis frei sein, eim jetlichen } \\
\text { sein Notdurft ins Haus zu } \\
\text { brengen umsunst lassen } \\
\text { nehmen, auch wann } \\
\text { vonnöten sein wurde zu } \\
\text { zimmern, auch umsunst } \\
\text { nehmen, doch mit Wissen } \\
\text { der, so von der Gemein darzu } \\
\text { erwehlt werden. So aber } \\
\text { keins vorhanden wer, dann } \\
\text { das, so redlich erkauft ist } \\
\text { worden, soll man sich mit } \\
\text { denselbigen briederlich und } \\
\text { christelich vergleichen. } \\
\text { Wann aber das Gut am } \\
\text { Anfang aus ihnen selbs } \\
\text { geeignet wer worden und } \\
\text { nachmals verkauft worden, } \\
\text { soll man sich vergleichen } \\
\text { nach Gestalt der Sach und } \\
\text { Erkanntnus briederlicher } \\
\text { Lieb und Heiliger Geschrift. }\end{array}$ & $\begin{array}{l}\text { O quinto artigo. Em quinto } \\
\text { lugar, parece-nos graves } \\
\text { questões relativas ao corte de } \\
\text { madeira, porquanto que a } \\
\text { gente nobre se apropriou de } \\
\text { todos os bosques para seu } \\
\text { exclusivo uso pessoal. } \\
\text { Quando um homem pobre } \\
\text { necessita de madeira, deve } \\
\text { pagar o dobro por ela. É } \\
\text { nossa opinião, no que } \\
\text { concerne aos bosques que a } \\
\text { possessão de um Senhor, seja } \\
\text { espiritual ou temporal, que, a } \\
\text { menos que tenha sido } \\
\text { devidamente comprado, } \\
\text { deverá ser devolvido } \\
\text { novamente a comunidade. } \\
\text { Mais ainda: todo membro da } \\
\text { comunidade será livre para } \\
\text { procurar por si mesmo a } \\
\text { lenha necessária para seu lar. } \\
\text { Da mesma forma, se um } \\
\text { homem requer madeira para } \\
\text { usos de carpintaria, a obterá } \\
\text { sem encargo, mas com } \\
\text { conhecimento de uma pessoa } \\
\text { designada pela comunidade } \\
\text { com tal propósito. Não } \\
\text { obstante, nenhum bosque } \\
\text { devidamente comprado e } \\
\text { administrado de maneira } \\
\text { fraternal e cristã, será posto à } \\
\text { disposição da renda } \\
\text { comunidade. Se um bosque, } \\
\text { mesmo aquele que tiver sido } \\
\text { objeto de apropriação em } \\
\text { primeira instância, tiver sido } \\
\text { logo vendido na forma } \\
\text { devida, a questão será } \\
\text { dirimida com espírito } \\
\text { amistoso e de acordo com as } \\
\text { Sagradas Escrituras. }\end{array}$ \\
\hline
\end{tabular}




\begin{tabular}{|c|c|c|}
\hline $\begin{array}{l}\text { Der sechst artickel: } \\
\mathrm{Zu}(\mathrm{o}) \mathrm{m} \text { sechsten ist vnser } \\
\text { hart beschwerung der dyenst } \\
\text { halben, wo(e)lche von tag } \\
\mathrm{zu}(\mathrm{o}) \text { tag gemert werden vnd } \\
\text { teglich zu(o) nemen, begeren } \\
\text { wir, das man ain zimlich ein } \\
\text { sechen darein thu(e), vnß der } \\
\text { massen nit so hart } \\
\text { beschweren, sonder vns } \\
\text { gnedig hier jnnen ansechen, } \\
\text { wie vnser eltern gedient } \\
\text { haben, allain nach laut des } \\
\text { wort gots. }\end{array}$ & $\begin{array}{l}\text { Der sechst Artikel. } \\
\text { Zum sechsten ist unser hart } \\
\text { Beschwerung der Dienst } \\
\text { halben, wölche von Tag zu } \\
\text { Tag gemehrt werden und } \\
\text { teglich zunehmen. Begehren } \\
\text { wir, daß man ein ziemlich } \\
\text { Einsehen darein tu, uns } \\
\text { dermaßen nit so hart } \\
\text { beschweren, sonder uns } \\
\text { gnedig hierinnen ansehen, } \\
\text { wie unser Eltern gedient } \\
\text { haben allein nach Laut des } \\
\text { Wort Gotts. }\end{array}$ & $\begin{array}{l}\text { O sexto artigo. Em sexto } \\
\text { lugar, nossa queixa concerne } \\
\text { aos excessivos serviços que } \\
\text { nos são requeridos, os que se } \\
\text { multiplicam dia após dia. } \\
\text { Rogamos que esta questão } \\
\text { seja apropriadamente } \\
\text { examinada de modo tal que } \\
\text { não sejamos duramente } \\
\text { oprimidos, que tenham lugar } \\
\text { considerações para conosco, } \\
\text { porquanto que a nossos } \\
\text { antepassados só lhes era } \\
\text { requerido servir em } \\
\text { conformidade com a palavra } \\
\text { de Deus. }\end{array}$ \\
\hline $\begin{array}{l}\text { Der sybent artickel: } \\
\text { Zu(e)m sibenden, das wir } \\
\text { hinfüro vns ain herschafft nit } \\
\text { weyter wo(e)lle lassen } \\
\text { beschweren, sonder wieß ain } \\
\text { herschafft zymlicher weiß } \\
\text { aim verleycht, also sol erß } \\
\text { besitzen laut der verainigung } \\
\text { des herren vnd bauren. Der } \\
\text { herr soll jn nit weiter } \\
\text { zwyngen noch dryngen, mer } \\
\text { dyenst noch anders vom jm } \\
\text { vmb sunst begeren, darmit } \\
\text { der baur solych gu(o)tt } \\
\text { onbeschwert, also rüeblich } \\
\text { brauchen vnd niessen müg. } \\
\text { Ob aber des herren dienst } \\
\text { von no(e)tten weren, sol jm } \\
\text { der baur willig vnd gehorsam } \\
\text { für ander sein, doch zu(e) } \\
\text { stund vnd zeyt, das dem } \\
\text { bauren nit zu(o) nachtail } \\
\text { dyen, vnnd jme vmb aynen } \\
\text { zymlichen pffenning denn } \\
\text { thu(o)n. }\end{array}$ & $\begin{array}{l}\text { Der siebent Artikel. } \\
\text { Zum siebenten. Daß wir } \\
\text { hinfüro uns ein Herrschaft nit } \\
\text { weiter wöllen lassen } \\
\text { beschweren, sonder wies ein } \\
\text { Herrschaft ziemlicher Weis } \\
\text { eim verleiht, also soll ers } \\
\text { besitzen laut der Vereinigung } \\
\text { des Herren und Bauren. Der } \\
\text { Herr soll ihn nit weiter } \\
\text { zwingen noch dringen, mehr } \\
\text { Dienst noch anders von ihm } \\
\text { umsunst begehren, darmit der } \\
\text { Baur solich Gut } \\
\text { ohnbeschwert also rüeblich } \\
\text { brauchen und nießen müg. } \\
\text { Ob aber dem Herren Dienst } \\
\text { vonnöten weren, soll ihm der } \\
\text { Baur willig und gehorsam für } \\
\text { ander sein, doch zu Stund } \\
\text { und Zeit, daß dem Bauren nit } \\
\text { zu Nachteil dien und ihme } \\
\text { um einen ziemlichen } \\
\text { Pfenning Dienst tun. }\end{array}$ & $\begin{array}{l}\text { O sétimo artigo. Em sétimo } \\
\text { lugar, de agora em diante, } \\
\text { não mais admitiremos um } \\
\text { senhorio que nos oprima por } \\
\text { parte de nossos senhores e só } \\
\text { permitiremos que eles nos } \\
\text { exijam o que é justo e } \\
\text { apropriado em conformidade } \\
\text { com as palavras do acordo } \\
\text { entre o senhor e o camponês. } \\
\text { O senhor não deverá na } \\
\text { sequência forçar ou } \\
\text { pressionar por serviços ou } \\
\text { outros deveres, sem } \\
\text { pagamento e deverá permitir } \\
\text { o gozo tranquilo e pacífico } \\
\text { de suas possessões. O } \\
\text { camponês deverá ajudar, não } \\
\text { obstante, a seu senhor, } \\
\text { quando for necessário e no } \\
\text { tempo adequado, quando não } \\
\text { lhe for desvantajoso para ele } \\
\text { e mediante um pagamento } \\
\text { apropriado. }\end{array}$ \\
\hline
\end{tabular}




\begin{tabular}{|c|c|c|}
\hline $\begin{array}{l}\text { Der achtet artickel: } \\
\mathrm{Zu}(\mathrm{o}) \mathrm{m} \text { achten sey wir } \\
\text { beschwert, vnd der vil, so } \\
\text { gu(e)ter jnnen haben, das die } \\
\text { selbigen gu(e)ter die gült nit } \\
\text { ertragen kinden vnd die } \\
\text { bauren das jr darauff } \\
\text { einbiessen vnd verderben, } \\
\text { das die herschafft dieselbigen } \\
\text { gu(e)ter, erber leüe } \\
\text { besichtigen lassen vnd nach } \\
\text { der billikayt ain gylt } \\
\text { erscho(e)pff, damit der baur } \\
\text { sein arbait nit vmb sunst } \\
\text { thye, dann ain yetlicher } \\
\text { tagwercker ist seyns lons } \\
\text { wirdig. }\end{array}$ & $\begin{array}{l}\text { Der achtet Artikel. } \\
\text { Zum achten sei wir } \\
\text { beschwert, und der viel, so } \\
\text { Güter innen haben, daß } \\
\text { dieselbigen Güter die Gült nit } \\
\text { ertragen kinden und die } \\
\text { Bauren das Ihr darauf } \\
\text { einbießen und verderben. } \\
\text { Daß die Herrschaft } \\
\text { dieselbigen Güter Erberleut } \\
\text { besichtigen lassen und nach } \\
\text { der Billigkeit ein Gilt } \\
\text { erschöpf, damit der Baur sein } \\
\text { Arbeit nit umsunst tue, dann } \\
\text { ein jetlicher Tagwerker ist } \\
\text { seins Lohns wirdig. }\end{array}$ & $\begin{array}{l}\text { O oitavo artigo. Em oitavo } \\
\text { lugar, nós somos oprimidos, } \\
\text { e de fato muito oprimidos, } \\
\text { por possessões que não } \\
\text { podem fazer frente às rendas } \\
\text { exigidas sobre aquelas. Os } \\
\text { camponeses sofrem desta } \\
\text { maneira perdas e estão } \\
\text { arruinados. Pedimos aos } \\
\text { senhores que designem } \\
\text { pessoas honradas para } \\
\text { estudar as possessões e fixar } \\
\text { rendas de acordo com a } \\
\text { justiça, de tal maneira que os } \\
\text { camponeses não estejam } \\
\text { obrigados a trabalhar em } \\
\text { troca de nada, seu labor é } \\
\text { digno de ser recompensado. }\end{array}$ \\
\hline $\begin{array}{l}\text { Der neundt artickel: } \\
\mathrm{Zu}(\mathrm{o}) \mathrm{m} \text { neünten seyen wyr } \\
\text { beschwertt der grossen frefel, } \\
\text { so man stetz new satzung } \\
\text { macht, nit das man vnß } \\
\text { strafft nach gestalt der sach, } \\
\text { sunder zu(o) zeyten auß } \\
\text { grossem neyd vnd zu(o) } \\
\text { zeytten auß grossem gunst. } \\
\text { Ist vnser maynung, vns bey } \\
\text { alter geschribner straff } \\
\text { straffen, darnach die sach } \\
\text { gehandelt ist, vnd nit nach } \\
\text { gunst. }\end{array}$ & $\begin{array}{l}\text { Der neunt Artikel. } \\
\text { Zum neunten seien wir } \\
\text { beschwert der großen Frevel, } \\
\text { so man stets neu Satzung } \\
\text { macht. Nit daß man uns straft } \\
\text { nach Gestalt der Sach, sunder } \\
\text { zu Zeiten aus großem Neid } \\
\text { und zu Zeiten aus großem } \\
\text { Gunst. Ist unser Meinung, } \\
\text { uns bei alter, geschriebner } \\
\text { Straf strafen, darnach die } \\
\text { Sach gehandelt ist, und nit } \\
\text { nach Gunst. }\end{array}$ & $\begin{array}{l}\text { O nono artigo. Em nono } \\
\text { lugar, ultraja-nos } \\
\text { grandemente a constante } \\
\text { promulgação de novas leis. } \\
\text { Não somos julgados em } \\
\text { relação à ofensa cometida, } \\
\text { mas antes às vezes com } \\
\text { enorme má vontade, às vezes } \\
\text { com indulgência. Em nossa } \\
\text { opinião, devemos ser } \\
\text { julgados em conformidade } \\
\text { com o antigo direito escrito e } \\
\text { o caso deverá ser decidido de } \\
\text { acordo com os méritos } \\
\text { próprios do caso e não } \\
\text { arbitrariamente. }\end{array}$ \\
\hline $\begin{array}{l}\text { Der zehent artickel: } \\
\mathrm{Zu}(\mathrm{o}) \mathrm{m} \text { zehenden sey wir } \\
\text { beschwert, das etlich haben } \\
\text { jnen zu(e)geaignet wisen, der } \\
\text { gleichen ecker, die dann } \\
\text { ainer gemain zu(o) } \\
\text { geherendt. Dieselbigen } \\
\text { werden wir wider zu(e) } \\
\text { vnsern gemainen handen } \\
\text { nehmen, es sey dann sach, } \\
\text { das mans redlich erkaufft } \\
\text { hab. Wann mans aber } \\
\text { vnbillycher weyß erkaufft } \\
\text { het, sol man sich gu(e)tlich } \\
\text { vnnd briederlich mit ainander } \\
\text { vergleychen nach gestalt der } \\
\text { sach. }\end{array}$ & $\begin{array}{l}\text { Der zehent Artikel. } \\
\text { Zum zehenten sei wir } \\
\text { beschwert, daß etlich haben } \\
\text { ihnen zugeeignet Wiesen, } \\
\text { dergleichen Ecker, die dann } \\
\text { einer Gemein zugeherent. } \\
\text { Dieselbigen werden wir } \\
\text { wieder zu unsern gemeinen } \\
\text { Händen nehmen; es sei dann } \\
\text { Sach, daß mans redlich } \\
\text { erkauft hab. Wann mans aber } \\
\text { unbillicher Weis erkauft hett, } \\
\text { soll man sich gütlich und } \\
\text { briederlich miteinander } \\
\text { vergleichen nach Gestalt der } \\
\text { Sach. }\end{array}$ & $\begin{array}{l}\text { O décimo artigo. Em décimo } \\
\text { lugar, somos molestados pela } \\
\text { apropriação, por alguns } \\
\text { indivíduos, de prados e } \\
\text { campos que outrora } \\
\text { pertenceram à comunidade. } \\
\text { Tomaremos possessão } \\
\text { novamente, para nossas mãos } \\
\text { em comum, dos ditos } \\
\text { campos. Não obstante, cabe } \\
\text { que estes campos tenham } \\
\text { sido adquiridos conforme o } \\
\text { direito. Quando, de maneira } \\
\text { injusta, as terras tenham sido } \\
\text { assim adquiridas, um arranjol } \\
\text { acordo fraternal deverá ter } \\
\text { lugar de acordo com as } \\
\text { circunstâncias. }\end{array}$ \\
\hline
\end{tabular}




\begin{tabular}{|c|c|c|}
\hline $\begin{array}{l}\text { Der aylfft artickel: } \\
\text { Zu(o)m ailften wellen wir } \\
\text { den brauch genant den todt } \\
\text { fall gantz vnd gar abthu(e)n } \\
\text { haben. Den nimmer leiden } \\
\text { noch gestatten, das man } \\
\text { witwen, waisen das jr wider } \\
\text { got vnd eeren, also schentlich } \\
\text { nemen, berauben sol, wie es } \\
\text { an vil ortten (menigerlay } \\
\text { gestalt) geschehen ist, vnd } \\
\text { von den, so sy besitzen vnd } \\
\text { beschirmen solten, hand sy } \\
\text { vns geschunden vnnd } \\
\text { geschaben, vnd wann sy } \\
\text { wenig fu(o)g hettendt gehabt, } \\
\text { hettendt diß gar genomen, } \\
\text { das got nit mer leiden wyl, } \\
\text { sunder sol gantz absein, kain } \\
\text { mensch nichts hinfiro } \\
\text { schuldig sein zu(o) geben, } \\
\text { weder wenig noch vyl. }\end{array}$ & $\begin{array}{l}\text { Der eilft Artikel. } \\
\text { Zum eilften wellen wir den } \\
\text { Brauch, genannt den Todfall, } \\
\text { ganz und gar abtun haben, } \\
\text { den nimmer leiden noch } \\
\text { gestatten, daß man Witwen, } \\
\text { Waisen das Ihr wider Gott } \\
\text { und Ehren also schendlich } \\
\text { nehmen, berauben soll, wie } \\
\text { es an viel Orten (mennigerlei } \\
\text { Gestalt) geschehen ist, und } \\
\text { von den, so sie beschitzen } \\
\text { und beschirmen sollten; hant } \\
\text { sie uns geschunden und } \\
\text { geschaben, und wann sie } \\
\text { wenig Fug hettent gehabt, } \\
\text { hettent sies gar genommen, } \\
\text { das Gott nit mehr leiden will, } \\
\text { sunder soll ganz absein, kein } \\
\text { Mensch nichts hinfiro } \\
\text { schuldig sein zu geben, } \\
\text { weder wenig noch viel. }\end{array}$ & $\begin{array}{l}\text { O undécimo artigo. Em } \\
\text { undécimo lugar, aboliremos } \\
\text { total e completamente o } \\
\text { chamado tributo por caso de } \\
\text { morte (Todfall). Não o } \\
\text { sofreremos em absoluto de } \\
\text { hoje em diante, nem } \\
\text { tampouco toleraremos que } \\
\text { viúvas e órfãos sejam } \\
\text { desavergonhadamente } \\
\text { roubados contra a vontade de } \\
\text { Deus, com violação da } \\
\text { justiça e do direito, como } \\
\text { sucedeu em tantos lugares } \\
\text { pela obra justamente } \\
\text { daqueles que teriam que tê- } \\
\text { los resguardado e protegido. } \\
\text { Esses nos têm levado a } \\
\text { desgraça e não têm } \\
\text { espoliado, em que pese a ter } \\
\text { escassos fundamentos, assim } \\
\text { nos têm usurpado. Deus não } \\
\text { o admitirá nunca mais, isto } \\
\text { será radicalmente suprimido } \\
\text { e ninguém no futuro será } \\
\text { obrigado a dar nem pouco } \\
\text { nem muito. }\end{array}$ \\
\hline $\begin{array}{l}\mathrm{Zu}(\mathrm{o}) \mathrm{m} \text { zwelften ist vnser } \\
\text { beschluß vnd endtlyche } \\
\text { maynung, wann ainer oder } \\
\text { mer artickel, alhie gesteldt } \\
\text { (so dem wort gotes nit } \\
\text { gemeß) weren, als wir dann } \\
\text { nit vermainen, die selbigen } \\
\text { artickel wol man vns mit } \\
\text { dem wort gots für vnzimlich } \\
\text { anzaigen, wolt wyr daruon } \\
\text { abston, wann mans vns mit } \\
\text { grundt der schrifft erklert. Ob } \\
\text { man vns schon etlich artickel } \\
\text { yetz zu(o) lyeß vnd hernach } \\
\text { sich befendt, das vnrecht } \\
\text { weren, sollen sy von stund an } \\
\text { todt vnd absein, } \| \text { nichts mer } \\
\text { gelten. Dergleichen ob sich } \\
\text { in der schrifft mit der warhait } \\
\text { mer artickel erfunden, die } \\
\text { wider got vnd beschwernus } \\
\text { der na(e)chsten weren, } \\
\text { wo(e)ll wir vnns auch } \\
\text { vorbehalten vnnd }\end{array}$ & $\begin{array}{l}\text { 12.Ist unser Beschluss und } \\
\text { endliche Meinung, wenn } \\
\text { einer oder mehr der hier } \\
\text { gestellten Artikel dem Worte } \\
\text { Gottes nicht gemäß wären } \\
\text {.., von denen wollen wir } \\
\text { abstehen, wenn man es uns } \\
\text { auf Grund der Schrift erklärt. } \\
\text { Wenn man uns schon etliche } \\
\text { Artikel jetzt zuließe und es } \\
\text { befände sich hernach, dass } \\
\text { sie Unrecht wären, so sollen } \\
\text { sie von Stund an tot und ab } \\
\text { sein. Desgleichen wollen wir } \\
\text { uns aber auch vorbehalten } \\
\text { haben, wenn man in der } \\
\text { Schrift noch mehr Artikel } \\
\text { fände, die wider Gott und } \\
\text { eine Beschwernis des } \\
\text { Nächsten wären. }\end{array}$ & $\begin{array}{l}\text { Em duodécimo lugar, é nossa } \\
\text { conclusão e resolução final, } \\
\text { que se um ou mais artigos } \\
\text { dos que expostos não } \\
\text { estivessem de acordo com a } \\
\text { palavra de Deus, como nós } \\
\text { cremos que estão, } \\
\text { voluntariamente retiraremos } \\
\text { tal artigo quando se prove } \\
\text { que realmente é contrário a } \\
\text { palavra de Deus mediante } \\
\text { uma clara explicação da } \\
\text { Escritura. Ou se os artigos } \\
\text { que agora que se nos } \\
\text { concedem (?), descobrir-se } \\
\text { ulteriormente que são } \\
\text { injustos, a partir deste } \\
\text { momento ter-se-ão por letra } \\
\text { morta, por nulos e sem } \\
\text { efeito. Da mesma forma, se } \\
\text { descobrirem-se novos } \\
\text { agravantes baseados na } \\
\text { verdade e na Escritura e } \\
\text { relacionados com ofensas a }\end{array}$ \\
\hline
\end{tabular}




\begin{tabular}{|c|c|}
\hline $\begin{array}{l}\text { beschlossen haben vnnd vns } \\
\text { in aller christlicher leer } \\
\text { yeben vnd brauchen. Darumb } \\
\text { wir gott den herren bitten } \\
\text { wo(e)llen, der vns das selbig } \\
\text { geben kan vnnd sunst } \\
\text { nyemant. Der frid Christi sey } \\
\text { mit vns allen." }\end{array}$ & $\begin{array}{l}\text { Deus ou a nosso próximo, } \\
\text { resolveremos reservar o } \\
\text { direito de expô-los e pôr em } \\
\text { prática, nós mesmos, todas os } \\
\text { ensinamentos cristãos. Por } \\
\text { tudo isso, rogaremos a Deus } \\
\text { porque Ele e só Ele pode } \\
\text { conceder-nos o solicitado. } \\
\text { Que a paz de Cristo } \\
\text { permaneça em todos nós. }\end{array}$ \\
\hline
\end{tabular}

Não nos é possível extrair todas as consequências deste Manifesto para as ações de Lutero, Müntzer e para o Homem Comum. Os pontos são tantos e com tantas direções que faríamos um outro trabalho. Basta lembramos de duas obras: a primeira de Lutero: Ermahnung zum Frieden auf die 12 Artikel der Bauernschaft Schwaben (Exortação à Paz em relação aos 12 artigos do campesinato na Suábia), de abril de 1525. Ainda que critique abertamente alguns pontos do artigo, termina o texto por admoestar os senhores feudais para que abandonem "um pouco de vossa tirania e opressão" (ein wenig von eurer Tyrannei und Unterdrückung) (LUTHER, 1848 [1525]: 75), para que com isto "também o homem pobre ganhe ar e terra para viver" (damit auch der arme Mann Luft und Raum gewänne zum Leben) (LUTHER, 1848 [1525]: Idem). Em Münzer não é diferente. Há décadas imputavam-lhe até mesmo a autoria sem, no entanto, poderem confirmar com provas definitivas.

Temor e tremor caibam aqueles que perpetram o mal (Rom. 2, 9); dá-me pena, que deste modo abuses da Epístola de Paulo. Queres através disto confirmar a mais celerada autoridade sobre todo o povo, como o Papa reduziu Pedro e Paulo a carcereiros (...) Achas que Deus não está mais com Seu povo, e sim convosco tiranos? (...) Queres ser um pagão sob o nome de Cristo e esconderte sob o nome de São Paulo; porém te será cortado o caminho, saibas, portanto, conter-te, se quiseres reconhecer, com Daniel no $7^{\circ}$. Cap., que Deus transmitiu o poder à comunidade, aparecendo diante de nós quebrando tua fé, então te aceitaremos bem e te olharemos como a um irmão. (Carta de Münzer ao conde Albrecht, 12 de maio de 1525) (VOGLER, 2003: 126-143) 9

Aqui e ali, em suas correspondências, pululam remissões aos 12 artigos (BLOCH, 1973: 59). Não se trata, pois, de ordens expedidas pelos príncipes ou conjecturas sobre o

\footnotetext{
${ }^{9}$ Citado também por BLOCH, 1973: 66.
} 
quadro econômico. A revolução do homem comum exige extirpar da sociedade (leia-se clero, nobreza e burguesia) todo o mal. A Burguesia crê em Deus, mas, por meio de uma teologia afeita a seus caprichos, crê em Deus de um modo pagão. Fazê-los aceitar a palavra de Deus de maneira com está fundada nas Escrituras (vnd in dieser gestalt in der geschrifft gegrindt) é a missão dos camponeses, em relação aos quais Lutero e Münzer serão meros coadjuvantes. E em ambos os casos, em Lutero e em Münzer, em nada a crença em Deus se assemelha ao ópio do povo. É puro fogo de rastilho que despertará a cólera dos príncipes e levará a uma explosão de violência com o saldo de cerca 100.000 mil camponeses mortos (SCHINDLING, 1994: 87-88).

\section{Ensaio de uma conclusão}

A guerra dos camponeses foi sem dúvida um acontecimento ímpar. Cheia de contradições, a luta dos camponeses pela terra e por condições dignas de trabalho trouxe à tona uma religião sem clero, uma teologia sem sacerdote, um movimento de massa em que as principais personagens Lutero, Münzer, burgueses, nobres e clero ficaram a reboque de líderes, a exemplo do manifesto, anônimos, homens comuns. Queriam modificar o mundo a sua volta sem grandes vôos e, no entanto, se lançaram de uma grande altitude. Talvez esteja aqui bálsamo do significado do protestantismo histórico. Infelizmente a teologia e, não a crença, venceu. Vale a pena neste ponto uma passagem de Karl Marx sobre o fato.

(...) se o protestantismo não foi a verdadeira solução, representou a verdadeira colocação do problema. Já não se tratava da luta do leigo com o sacerdote que existe fora dele, mas da luta com o sacerdote que existe dentro de si próprio, com sua natureza sacerdotal. E, se a transformação protestante do leigo alemão em sacerdote emancipou os papas leigos, os príncipes, com toda sua clerezia, os privilegiados e os filisteus, a transformação filosófica dos alemães com espírito sacerdotal em homens emancipará o povo. Mas, do mesmo modo que a emancipação não se deteve nos príncipes, tampouco a secularização dos bens se deterá no despojo da igreja, (...). Outrora, a guerra dos camponeses, fato mais radical da história alemã, malogrou na teologia. ${ }^{10}$.

\footnotetext{
${ }^{10}$ Karl Marx/ Friedrich Engels - Werke. (Karl) Dietz Verlag, Berlin. Band 1. Berlin/DDR. 1976. S. 378391, esp. 386. (...) wenn der Protestantismus nicht die wahre Lösung, so war er die wahre Stellung der Aufgabe. Es galt nun nicht mehr den Kampf des Laien mit dem Pfaffen außer ihm, es galt den Kampf mit
} 


\section{Fontes}

FRANZ, Günther (1963). Quellen zur Geschichte des Bauernkrieges. Darmstadt: WBG, pp. 174-79.

WALDAU, Georg Ernst (1791). Materialien zur Geschichte des Bauernkriegs in Franken, Schwaben, Thüringen im Jahr 1525. Karl Gottlieb Hoffmann, Chemnitz.

\section{Referências Bibliográficas}

ANGERMEIER, Heinz. (1966). Die Vorstellung des „gemeinen Mannes" von Staat und Reich im Bauernkrieg. In: Vierteljahrsschrift für Sozial- und Wirtschaftsgeschichte 53, Caderno 3, pp.329-343.

BLICKLE, Peter. (2012). Der Bauernkrieg. Die Revolution des Gemeinen Mannes. 4a. ed. C.H. BECK. Munique.

BLOCH, Ernst (1973). Thomas Münzer. Teólogo da Revolução. Biblioteca Tempo Universitário, 34. Rio de Janeiro: Tempo Brasileiro.

FRANZ, Günther. (1933). Der deutsche Bauernkrieg. 1a . edição. Munique.

FISCHER, Wolfram. (1977). Gewinn- und Leistungsorientierung in sozialhistorischer Perspektive. In: HARTFIEL, Günther (Org). Das Leistungsprinzip: Merkmale Bedingungen - Probleme. Verlag: Opladen, Leske und Budrich.

HOCKERTS, Hans Günter. (1979) Der Bauernkrieg 1525 - frühbürgerliche Revolution, defensive Bauernerhebung ou der Revolution des "gemeinen Mannes"? In: ERDMANN, K. D.; MESSERSCHMID, F. e ROHLFES, J. (Orgs.) Geschichte in Wissenschaft und Unterricht. Zeitschrift des Verbandes der Geschichtslehrer Deutschlands. 30, Stuttgart: Ernst Klett, pp. 1-20.

KULA, Witold (1962). Teoria Econômica do Sistema Medieval. PortugallBrasil: Editorial PresençalLivraria Martins Fontes.

LAFARGUE, Paul (1985). Por qué cree en Dios la Burguesia. Pourquoi la Bourgeoise croit en Dieu. Trad. Julio Arostegui. Buenos Aires: Ed. Leviatán.

LUTHER, Martin (1848[1525]). Ermahnung zum Frieden auf die zwölf Artikel der Bauernschaft in Schwaben: Vol. 4. Wittenberg. J. A. Barth

MARX, Karl \&, ENGELS, Friedrich (1976). Zur Kritik der Hegelschen Rechtsphilosophie. Werke. (Karl) Dietz Verlag, Berlin. Band 1. Berlin/DDR.

MÜLLER, Jürgen (2013). Martin Luther \& Thomas Müntzer.Ihr Leben und Ihre Zeit sowie ihre reformatorische Wirkungen auf die Ereignisse des deutschen Bauernkrieges von 1524 - 1525. Abschlussarbeit. Goethe-Universität. Frankfurt am Main.

PERNOUD, Régine. (1965). Les origines de la bourgeoisie. Paris: P.U.F. (Col. Que saisje? Nr. 269.

RANKE, Leopond von. (1909 [1839]) Deutsche Geschichte im Zeitalter der Reformation. Vol. II. Leipzig: Dunker und Humblot.

seinen eigenen innern Pfaffen, seiner pfäffischen Natur. Und wenn die protestantische Verwandlung der deutschen Laien in Pfaffen die Laienpäpste, die Fürsten samt ihrer Klerisei, den Privilegierten und den Philistern, emanzipiert, so wird die philosophische Verwandlung der pfäffischen Deutschen in Menschen das Volk emanzipieren. Sowenig aber die Emanzipation bei den Fürsten, sowenig wird aber die Säkularisation der Güter bei dem Kirchenraub stehenbleiben, (...). Damals scheiterte der Bauernkrieg, die radikalste Tatsache der deutschen Geschichte, an der Theologie (Grifos do autor). 
SCHINDLING, Anton. (1994) - Bauernkrieg. KASPER, WALTER et alii (Org.). Lexikon für Theologie und Kirche. Vol. 2. Barclay bis Damodos $3^{\mathrm{a}}$. edição. Freiburg|BasellRomlWien: Herder.

STONE, Lawrence (1970). The English Revolution. In: FOSTER, R.; GREENE, P. (Orgs.): Preconditions of Revolutions in Early Modern Europe. Baltimore-London, pp. 55-108.

THOMAS, Ulrich (1976-1977). Bibliographie zum deutschen Bauernkrieg und seiner Zeit. Stuttgart: Fachdokumentationsstelle für Agrargeschichte im Inst. für Sozialwissenschaft. Volume 1, 1976 e Volume 2, 1977.

VOGLER, Günter, Thomas Müntzers Briefe an die Grafen Albrecht und Ernst von Mansfeld vom 12. Mai 1525. Ein Interpretationsversuch. In: Günter Vogler, Thomas Müntzer und die Gesellschaft seiner Zeit (Thomas-MüntzerGesellschaft e.V. Veröffentlichungen, Vol. 4.) Mühlhausen 2003, pp. 126-143, apud BLOCH, Ernst. Thomas Münzer. Teólogo da Revolução. Biblioteca Tempo Universitário, 34. Rio de Janeiro: Tempo Brasileiro. 1973, pg. 66.

ZIMMERMANN, Wilhelm. (1842). Allgemeine Geschichte des grossen Bauernkrieges nach handschriftlichen und gedruckten Quellen. Franz Heinrich Köhler. Stuttgart.

ZORN, WOLFGANG (1971). Sozialgeschichte 1500-1648. In: HERMANN, AUBIN; ZORN, WOLFGANG et alii (Orgs.): Handbuch der deutschen Wirtschafts- und Sozialgeschichte: Von der Frühzeit bis zum Ende des 18. Jahrhunderts, Vol. 1. Stuttgart. 